\title{
GÊNERO POÉTICO: UMA PROPOSTA EM ESPIRAL PARA O ENSINO FUNDAMENTAL ॥
}

\author{
Norma Seltzer Goldstein*
}

\begin{abstract}
RESUMO: O trabalho com poesia torna-se particularmente significativo numa proposta de ensino "em espiral". Nessa perspectiva, este texto propõe um eixo vertical para o trabalho com o poema no ensino fundamental II: I) leitura e reconhecimento das características textuais de poemas tradicionais regulares na $5^{\mathrm{a}}$ série e irregulares, na $6^{\mathrm{a}}$ série; II) prosa poética e poema em prosa, na $7^{\mathrm{a}}$ série; III) poesia visual, na $8^{\mathrm{a}}$ série, considerando que, no contexto escolar, o ensino de língua materna deve ser contextualizado.
\end{abstract}

PALAVRAS-CHAVE: Gênero poético na escola; Leitura de poesia; Poema e estudo da língua.

1. 0

oda atividade didática deve ocorrer de modo contexT tualizado. Creio que isso seja possível, sem deixar de abrir espaço para o texto poético, ao longo das quatro séries do Ensino Fundamental II, num processo "em espiral" (Dolz e Pasquier, 1996), com gradual aprofundamento, a cada retomada. Dizendo de outra forma, o trabalho com poesia deveria, sempre, iniciar pelo levantamento do conhecimento prévio dos alunos a respeito, relendo e comentando poemas com características já conhecidas por terem sido lidos em séries anteriores, antes de introduzir novos modos de composição do gênero. É essencial que sejam estabelecidos paralelos, permanentemente, en-

Universidade de São Paulo 
tre as leituras mais recentes e as mais antigas, apontando semelhanças e diferenças entre os diferentes tipos de textos poéticos. Metaforicamente, esse movimento de ida e vinda, com gradativa ampliação, lembra o desenho da espiral. Explicito adiante algumas propostas para apoiar esse modo de trabalhar o poema no Ensino Fundamental II.

Considero viável que, na $5^{\mathrm{a}}$ série, se privilegie o estudo de poemas regulares; na $6^{\mathrm{a}}$, o poema regular seja retomado como ponto de partida para a introdução de poemas irregulares; na $7^{\mathrm{a}}$, se faça a passagem do poema em versos para dois outros gêneros: a prosa poética e o poema em prosa; e na $8^{a}$, o estudo se amplie para a poesia visual.

$\mathrm{Na} 5^{\mathrm{a}}$ série, o ponto de partida seria o resgate do conhecimento prévio dos alunos que, muito provavelmente, terão ouvido ou lido parlendas, jogos sonoros como os trava-línguas, quadrinhas e alguns poemas, ao longo do Ensino Fundamental I. O primeiro objetivo volta-se para a leitura e o reconhecimento das características do gênero, assim como das marcas que o distinguem dos gêneros não poéticos $\mathrm{O}$ segundo teria como foco a montagem de oficinas de produção poética, sem que se pretenda "produzir poetas", mas principalmente motivar e aguçar a percepção dos alunos para as características e as marcas linguiísticas do poema - que, eventualmente, também podem surtir efeitos de sentido, se forem empregadas, depois, em passagens de suas próprias produções. Limito-me, aqui, a apontar sugestões voltadas para o primeiro objetivo.

Da $5^{\mathrm{a}}$ a $8^{\mathrm{a}}$ séries, o ponto de partida consistiria sempre na retomada do trabalho da série anterior, recuperando noções já conhecidas, para ampliá-las e aprofundá-las.

Em cada série, um conjunto de noções importantes deve ser trabalhado. Na organização das sequiências didáticas, haveria inúmeras escolhas possíveis. A título de exemplificação, sugiro um "elenco" de possibilidades, sem a pretensão de esgotar o tema. 
Filol. lingüíst. port., n. 8, p. 361-377, 2006.

2.0

Na $5^{\mathrm{a}}$ série, uma das atividades iniciais seria conduzir os alunos a perceber a distinção entre o texto em versos - nos quais a finalidade poética é secundária - e o poema propriamente dito no qual ela é prioritária -, como ilustra o paralelo entre os textos (1) e (2), criados pela mesma autora:

(1)

$\mathrm{T}$

(...)

Ta-tá-rá-tá-tá,

Ora o $\mathbf{T}$ como bate,

como bate, bate, bate

no seu Tamborim!

Esse $\mathbf{T}$ da Travessura,

que é o $\underline{T}$ do Trambolhão

se dá Tombo lá de cima,

quebra a Testa no chão!

Ta-tá-rá-tá-chim!

Lá do Trampolim,

o T diz assim:

"É de Tomate, de Tomate e Tomatada,

pra fazer cara vermelha,

pra fazer boca encarnada

que nem Telha!

É de Tomate, é de Tomate, é de Tomate!"

- E o $\underline{T}$ bate e bate -

Todo de escarlate.

(..)

Cecília Meireles. Festa das Letras. Rio de Janeiro: Nova Fronteira, 1996. 
GOLDSTEIN, Norma Seltzer. Gênero poético: uma proposta em espiral para o ensino...

(2)

O ECO

O menino pergunta ao eco

onde é que ele se esconde.

Mas o eco só responde: "Onde? Onde?"

O menino também lhe pede:

"Eco, vem passear comigo!"

Mas não sabe se o eco é amigo

ou inimigo.

Pois só lhe ouve dizer: "Migo!"

Cecília Meireles. Ou isto ou aquilo. 5. ed., Rio de Janeiro: Civilização Brasileira, 1981, p. 82.

Um dos elementos que os alunos rapidamente aprendem a buscar é a autoria e/ou o suporte em que está publicado o texto lido. Nos dois casos, a fonte é um livro da mesma autora que a maioria dos estudantes ao final do Ensino Fundamental I provavelmente já identifique como poetisa. Imaginemos esses alunos diante da seguinte questão: “qual dos dois é um poema?” É provável que apontassem ambos os textos, por reconhecerem a autoria. E possivelmente encontrem, em ambos, algumas características do poema: modo como o texto ocupa a página, com uma margem antes e outra depois; divisão em estrofes ou agrupamento de versos; acentuada marcação rítmica apoiada em repetições de letras e rimas.

No entanto, há uma diferença marcante entre eles. No primeiro, edição fac-similar do manual de alfabetização e saúde redigido por Cecília Meireles em co-autoria com o Dr. Josué de Castro -, os versos estão a serviço do ensinamento e as rimas, da memorização. Nessa obra, há um poema para cada letra, ilustrando como esse sinal gráfico se faz presente em vocábulos relativos à saúde, à higiene, à alimentação e ao comportamento que as crianças devem aprender a apreciar. Dada a habilidade criativa da poetisa, avultam recursos sonoros envolvendo a letra-título que encabeça 
o conjunto de versos a ela dedicados. O processo é retomado para cada letra do alfabeto, por vezes mencionando seu "desenho", num apoio à criança que aprende a escrever: "... o A com a sua cartolinha bicuda, // parece o chefe do batalhão”; “... O de Olho-vivo // e da cara redonda”; “... Mas que X preguiçoso, // só de perna cruzada!” No caso do exemplo acima, dedicado à letra " $T$ ", nossos grifos acrescentados ao texto evidenciam os efeitos sonoros da aliteração do fonema em destaque.

Sem dúvida, Festa das Letras desperta interesse e curiosidade. Pode-se falar em versos e efeitos rítmicos, mas não seria adequado considerar os textos do manual como poemas no sentido pleno da palavra. De certo modo, percebe-se na obra a engenhosidade de Cecília Meireles que busca convencer os pequenos leitores a bem se cuidar e bem se alimentar, enquanto fixam o papel fônico e ortográfico dos elementos do alfabeto.

O texto (2) tem caráter diverso. O título faz alusão ao mecanismo de repetição da parte final das palavras, quando pronunciadas em local onde haja eco. Ao ilustrar o que vem a ser o eco, o poema projeta esse conceito sobre um dos seus principais recursos sonoros: a rima. Trabalhando simultaneamente o plano da expressão e o do conteúdo, sobrepõem-se os aspectos sonoro, morfossintático e semântico, em duas ocorrências: na primeira, o termo "esconde" engloba "onde"; na segunda, o final "migo" coloca em relação os vocábulos por ele terminados: comigo/ amigo/ inimigo.

Numa leitura inicial, fica sugerido um jogo, uma brincadeira, apresentação da cena em que uma criança confunde o eco com um possível companheiro. Na releitura, os efeitos de repetição nos propõem ir além: que lugar o termo "onde" indicaria? Nossa busca (por lugares e pessoas) seria permanente? De que modo acontece o relacionamento entre pessoas? O amigo de hoje seria o inimigo de amanhã e vice-versa? Isso pode acontecer também "comigo"? Os contrários são sempre contrários?...

No plano metalinguiístico, esse processo se configura como uma alegoria da rima, ao mesmo tempo em que ilustra a organiza- 
GOLDSTEIN, Norma Seltzer. Gênero poético: uma proposta em espiral para o ensino...

ção do poema como texto a ser lido de duas formas diversas: a linear - como se lêem os demais textos - e a leitura específica do poema. Nessa forma de leitura, há um destaque especial para o significante, o que produz um efeito de sentido particular. Desse modo, o leitor é levado a relacionar os termos que se assemelham sonoramente e/ ou ocupam a mesma posição (no caso, final do verso), num processo de leitura vertical que se sobrepõe à leitura linear horizontal, tornando-se uma espécie de leitura em rede e ampliando a significação do texto.

Na comparação entre os dois textos, transparece que o texto (1) é um meio de divulgação, enquanto o (2) é uma finalidade em si mesmo, foi criado para ser um poema, para ser lido dessa perspectiva. Sem necessidade de teorizar ou citar autores, cremos ser possível levar alunos bem jovens a identificar as características e as marcas linguísticas de cada um desses textos, observando semelhanças e diferenças.

Nas séries seguintes, ao retomar o poema, conviria relembrar que ele permite mais de um modo de leitura, levando o leitor a buscar relações de sentido entre palavras com sons similares; ou que ocupam a mesma posição no verso; ou, ainda, que se situam em construções sintáticas do mesmo tipo, exercendo a mesma função. É preciso que o leitor busque elos de significação em diferentes direções, no interior do texto. Como retomada dos trabalhos realizados na $5^{\mathrm{a}}$ série, a escolha inicial deveria recair sobre um poema em versos predominantemente regulares - dentre aqueles que mais são empregados pelos poetas em língua portuguesa: de 5 sílabas ou redondilha menor; de 7 sílabas ou redondilha maior; de 10 sílabas ou decassílabo; ou de 12 sílabas ou alexandrino. Como ilustra a cantiga do contemporâneo Ferreira Gullar: 
Filol. lingüíst. port., n. 8, p. 361-377, 2006.

\section{CANTIGA PARA NÃO MORRER}

Quando você for se embora, moça branca como a neve, me leve.

Se acaso você não possa me carregar pela mão, menina branca de neve, me leve no coração.

Se no coração não possa por acaso me levar, moça de sonho e de neve, me leve no seu lembrar.

E se aí também não possa por tanta coisa que leve já viva em seu pensamento, menina branca de neve, me leve no esquecimento.

Ferreira Gullar. Toda poesia- 1950-1980. 2. ed. Rio de Janeiro: Civilização Brasileira, 1981, p. 285.

Os alunos conhecem esse poeta? Conviria apresentá-lo à classe, explicando que não escreve especificamente para jovens, mas algumas de suas criações podem ser compreendidas por eles, como este diálogo com a "moça de neve" que talvez evoque uma conhecida figura das histórias infantis.

É primordial explorar o ritmo, distribuído em estrofes desiguais: a primeira tem 3 versos, a segunda e a terceira, 4 e a última, 5 . O verso de 7 sílabas é o mais popular da língua, provavelmente por ser o mais simples quanto às regras de acentuação das sílabas poéticas: desde que a última se acentue, os demais acentos figuram em qualquer posição. É o ritmo predominante nas quadrinhas, 
nas canções populares, e nos versos narrativos das histórias de cordel.

O verso é o mesmo, ao longo do texto, com exceção do último verso da primeira estrofe que é menor. Ele é retomado de forma ampliada no verso final das demais estrofes, como uma espécie de refrão. Comparado aos outros versos finais, esse verso, visualmente, configura quase um meio verso, dando a pista para que os leitores o completem. Sonoramente, o fato de limitar-se apenas aos termos iniciais da retomada que virá adiante, prepara o efeito multiplicador do eco: de um verso, nos demais; do conto de fadas, no poema; do texto literário, na vida do leitor.

Em "Cantiga para não morrer", as rimas aparecem no final e no interior dos versos: são externas (neve) e internas (leve, nos versos 7,11 e 16). O poeta deseja que a moça de neve o leve com ela de alguma maneira: pela mão, no coração, no seu lembrar, em seu pensamento ou, ironicamente, no esquecimento.

Quem seria ela? Pessoa ou personagem? Figura real ou inventada? Ao longo do processo de leitura, podem ser recuperados vários elementos do repertório dos alunos sobre contos de fadas e lendas. Geralmente, nós é que levamos as figuras das lendas e das histórias na memória. Aqui, inverte-se o processo, no pedido para que a moça de neve transporte com ela a lembrança do poeta. Adulto ou criança? Só dele ou também do leitor: do poema ou das histórias de fadas? O que este tipo de leitura representa ou representou para cada um de nós? Se a moça de neve nos levar com ela, estaria assegurada a hipótese de mantermos vivas nossas ilusões?

Viria em seguida, do mesmo criador, um outro poema, com pontuação ausente e predominância de irregularidade:

MEU POVO, MEU POEMA

Meu povo e meu poema crescem juntos

como cresce no fruto

a árvore nova 
Filol. lingüíst. port., n. 8, p. 361-377, 2006.

\author{
No povo meu poema vai nascendo \\ como no canavial \\ nasce verde o açúcar \\ Meu povo meu poema está maduro \\ como o sol \\ na garganta do futuro \\ Meu povo em meu poema \\ se reflete \\ como a espiga se funde em terra fértil \\ Ao povo seu poema aqui devolvo \\ menos como quem canta \\ do que planta \\ Ferreira Gullar. Toda poesia- 1950-1980. 2.ed. Rio de Janeiro: Civilização Bra- \\ sileira, 1981, p. 217.
}

Visual e sonoramente, ressalta a organização formal do poema: versos desiguais compondo estrofes iguais de três versos ou tercetos. Mesclam-se regularidade estrófica e irregularidade rítmica ou métrica. Nesse poema, a temática remete a um traço marcante na poesia de Ferreira Gullar: o envolvimento com as questões sociais do país.

O título anuncia o paralelo entre a poesia e o povo. Na segunda e terceira estrofes, há comparações, aproximando o processo da criação ao da maturação do fruto e transformação da cana-deaçúcar. O terceto central, em nova comparação, recupera o papel do poeta como visionário e guia de seu povo, concepção Romântica de meados do século XIX: No povo, meu poema está maduro / como o sol / na garganta do futuro. Cabe ao poeta falar por seu povo e identificar-se com ele, como metaforizam os dois últimos tercetos. No poema contemporâneo, surge um elemento novo, ausente das criações românticas: a reciprocidade - o poeta é menos como quem canta / do que planta. 
GOLDSTEIN, Norma Seltzer. Gênero poético: uma proposta em espiral para o ensino...

O poema apresenta recursos rítmicos (como a aliteração de "p" em povo/poema), rimas toantes e consoantes. Há rimas na estrofe final, propondo que o leitor associe os verbos "plantar" e "cantar", buscando relacionar seu sentido: o canto do poeta, assim, seria equivalente ao plantio do agricultor. O leitor pode interpretar que, para o poeta, seus versos só fazem sentido se dialogarem com seus leitores; reciprocamente, em seus poemas devem ecoar a voz e os anseios do povo. Ao retomar a função social do poeta proposta pelo Romantismo, Ferreira Gullar a atualiza pela empatia e pela reciprocidade: o poeta contemporâneo conduz e inspira o povo, da mesma forma que é inspirado e conduzido por ele. Não fica isolado como o romântico, ao contrário: solidariza-se, mistura-se com seu povo, faz parte dele. Poeta e povo interagem reciprocamente.

Na sétima série, cabe comentar o efeito poético em textos em prosa de dois tipos: o poema em prosa e os trechos em prosa poética. Esta última aparece inserida em outro gênero em prosa. Já o poema em prosa é um texto completo, geralmente curto, com todas as características do poema, mesmo não sendo composto por versos.

Uma criação de Manoel de Barros ilustra o poema em prosa:

\section{SOBRE SUCATAS}

Isto porque a gente foi criada em lugar onde não tinha brinquedo fabricado. Isto porque a gente havia que fabricar os nossos brinquedos: eram boizinhos de osso, bolas de meia, automóveis de lata. Também a gente fazia de conta que sapo é boi de sela e viajava de sapo. Outra era ouvir nas conchas as origens do mundo. Estranhei muito quando, mais tarde, precisei de morar na cidade. Na cidade, um dia, contei para minha mãe que vira na Praça um homem montado no cavalo de pedra a mostrar uma faca comprida para o alto. Minha mãe corrigiu que não era uma faca, era uma espada. E o homem era um herói da nossa história. Claro que eu não tinha educação de cidade para saber que herói era um homem sentado num cavalo de pedra. Eles eram pessoas antigas da história que algum dia defenderam a 
Filol. lingüíst. port., n. 8, p. 361-377, 2006.

nossa Pátria. Para mim aqueles homens em cima da pedra eram sucata. Seriam sucata da história. Porque eu achava que uma vez no vento esses homens seriam como trastes, como qualquer pedaço de camisa nos ventos. Eu me lembrava dos espantalhos vestidos com as minhas camisas. O mundo era um pedaço complicado para o menino que viera da roça. Não vi nenhuma coisa mais bonita na cidade do que um passarinho. Vi que tudo que o homem fabrica vira sucata: bicicleta, avião, automóvel. Só o que não vira sucata é ave, árvore, rã, pedra. Até nave espacial vira sucata. Agora eu penso uma garça branca de brejo ser mais linda que uma nave espacial. Peço desculpas por cometer essa verdade.

Manoel de Barros. Memórias inventadas. São Paulo: Planeta, 2003, XV.

O primeiro e o segundo períodos começam de forma pouco usual: pelo pronome "isto", sugerindo a continuação de uma conversa anteriormente iniciada. Na mesma linha, o termo "a gente" exerce a função de sujeito, acentuando a sugestão de tom coloquial. Um pouco adiante, o verbo "tinha", com o sentido de "havia", reforça mais a indicação de informalidade. Apesar disso, o leitor não deve supor que o tom de conversa seja sinônimo de simplicidade, pois o texto é bastante elaborado e emprega recursos linguiísticos nos quais estão implícitas algumas pistas para sua interpretação.

O poema em prosa apresenta características que remetem ao poema em versos, isto é, emprega recursos que levam o leitor a buscar associações entre palavras do texto, numa leitura vertical complementar e superposta à horizontal, como ilustram alguns exemplos: i) repetição de vocábulos (isto, porque, a gente, cidade, homem, faca, herói, história, sucata, camisa, nave espacial); ii) repetições de letras: aliterações (boizinhos/bolas; cidade/ dia; homem / montado / morar / minha mãe / mundo; seriam sucata da história) e assonâncias (lembrava/ espantalhos / sucata/ pedaço; bonita/passarinho/ linda); iii) emprego de figuras como metáforas (ouvir nas conchas as origens do mundo; seriam sucata da história; o mundo era um pedaço complicado); comparações (esses homens seriam como trastes; como qualquer pedaço de camisa nos ventos; nenhuma coisa mais bonita do que um passarinho); enumerações (eram boizinhos de osso, bolas de meia, automóveis de lata; Tudo vira suca- 
GOLDSTEIN, Norma Seltzer. Gênero poético: uma proposta em espiral para o ensino...

ta: bicicleta, avião, automóvel; só o que não vira sucata é ave, árvore, rã, pedra; paralelismos (Isto porque a gente foi criada... / Isto porque a gente havia que fabricar...); ironia (Peço desculpas por cometer essa verdade).

$O$ fato de o texto apresentar o ponto de vista de um garoto envolve e seduz o leitor. A informação sobre ser um menino "da roça" que não tem "educação da cidade", de certo modo colocaria o leitor urbano em aparente posição de superioridade. Mas essa impressão se desfaz numa leitura atenta: as estátuas remetem a espantalhos, despojando-se de sua função heróica; as produções urbanas são vistas como futura sucata; a "roça" sai valorizada, na conclusão, pelo emprego inusitado do último verbo: cometer essa verdade. $\mathrm{O}$ tom irônico sugere, do ponto de vista do poeta, desmascarar a população urbana que se ilude, coletivamente, pensando, equivocadamente, viver no melhor dos mundos.

A prosa poética pode ser ilustrada por inúmeros trechos de alguns criadores de contos, romances e crônicas da segunda metade do século XX, como Clarice Lispector, Guimarães Rosa, J.J. Veiga e Rubem Braga. É deste último o exemplo que se segue:

(...) abri, em cada sala, as velhas lareiras. Umas com trempe, outras sem trempe, a todas enchi de lenha e pus fogo, vigiando sempre para ver se as chaminés funcionavam (...)

Todos tiveram o mesmo sentimento: apagar as luzes. Então eu passeava de sala em sala como um velho capitão, vigiando meus fogos que lançavam revérberos nos móveis e paredes, cuidando carinhosamente das chamas como se fossem grandes flores ardentes mas delicadas que iam crescendo graças ao meu amor. Lá fora o vento fustigava a chuva, na praça mal-iluminada; e vi, junto à luz triste de um poste, passarem flocos brancos que se perdiam na escuridão. Essa neve não caía do céu; eram as pequenas flores de uma árvore imensa que voavam naquela noite de inverno, sob a tortura do vento.

Rubem Braga, "A navegação da casa”. In: Os melhores contos. São Paulo: Global, 1985, p. 73.

Como no poema em prosa, também na prosa poética são empregados recursos que remetem ao poema em versos e pro- 
põem pistas para a interpretação. $O$ trecho poético, em meio à crônica, tem o efeito de criar uma espécie de suspensão do tempo e do relato, para, em seguida, retomar o fio condutor que vinha sendo seguido. A narrativa prossegue com novo alento, impregnada pelo efeito da passagem em prosa poética.

\section{0}

Na oitava série, após serem retomados tópicos das séries precedentes, seria importante alargar o estudo pela análise e interpretação do poema visual. A leitura de poemas concretos brasileiros poderia ser precedida por traduções de caligramas (textos com imagens superpostas aos versos, criados pelos gregos antigos), recriados pelo poeta francês Appolinaire, na primeira metade do século XX.

No caso dos poemas concretos, deve-se ressaltar que, nos anos 60 e 70 do século XX, o grupo homônimo explorou não só o aspecto visual dos textos, mas também o jogo de composição/decomposição de palavras. Depois, nos anos 70, um grupo de jovens artistas produziu criações alternativas, de modo artesanal, em mimeógrafos, nas quais também eram explorados os aspectos visuais e, em alguns casos, o mesmo jogo de desmembramento das partes componentes dos vocábulos.

Seguem-se alguns exemplos.

$$
\begin{gathered}
\text { forma } \\
\text { reforma } \\
\text { disforma } \\
\text { transforma } \\
\text { conforma } \\
\text { informa } \\
\text { forma }
\end{gathered}
$$


GOLDSTEIN, Norma Seltzer. Gênero poético: uma proposta em espiral para o ensino...

José Lino Grünewald. Poesia concreta. Seleção de textos, estudo crítico, biobibliográfico e histórico por lumna Maria Simon e Vinicius Dantas, Abril Educação, 1982.

Na criação de José Lino Grünevald, os vocábulos formados a partir do termo "forma" compõem visualmente uma espécie de balão, inflado pela forma que se reforma, transforma, disforma, conforma e informa no desenho composto pelas palavras do poema, exclusivamente nominal, marcado por essa sugestão estática, tensionada pela distribuição dinâmica das palavras na folha de papel. Também nesse poema concreto visual, a leitura linear deve ser complementada pela vertical, assim como pela sugestão da imagem do poema sobre o papel.

O poema "Gagarin", abaixo, foi criado por Cassiano Ricardo, em homenagem ao astronauta russo que expandiu as possibilidades de viajar pelo espaço. As palavras do poema se organizam circularmente, remetendo à sugestão de uma nave espacial.

O leitor percebe alguns jogos verbais, no arco superior do poema. O primeiro deles, em torno da palavra "ave", retomada em "nave", "belonave" e "astronave". A repetição "Belo belo" empresta o nome de um livro e um poema de Manuel Bandeira. Há um efeito de tensão criado pelo contraste entre a semelhança sonora e a diferença de sentido, nos vocábulos "belo" e "bélico", o primeiro relativo à beleza e o segundo, à guerra.

No centro, "pato selvagem ave" indicaria a formação do bando de aves, voando em conjunto. Um exemplo para os seres humanos?

No final, a intertextualidade remete ao leitor à época do César, saudado pelos que seriam sacrificados na arena, com a frase latina "morituri te salutant" (os que vão morrer te saúdam). Inversa e positivamente, o poeta anuncia: "os que vão nascer te saúdam". Trata-se da única forma verbal do poema, sugerindo diálogo dinâmico entre épocas e civilizações. 
Filol. lingüíst. port., n. 8, p. 361-377, 2006.

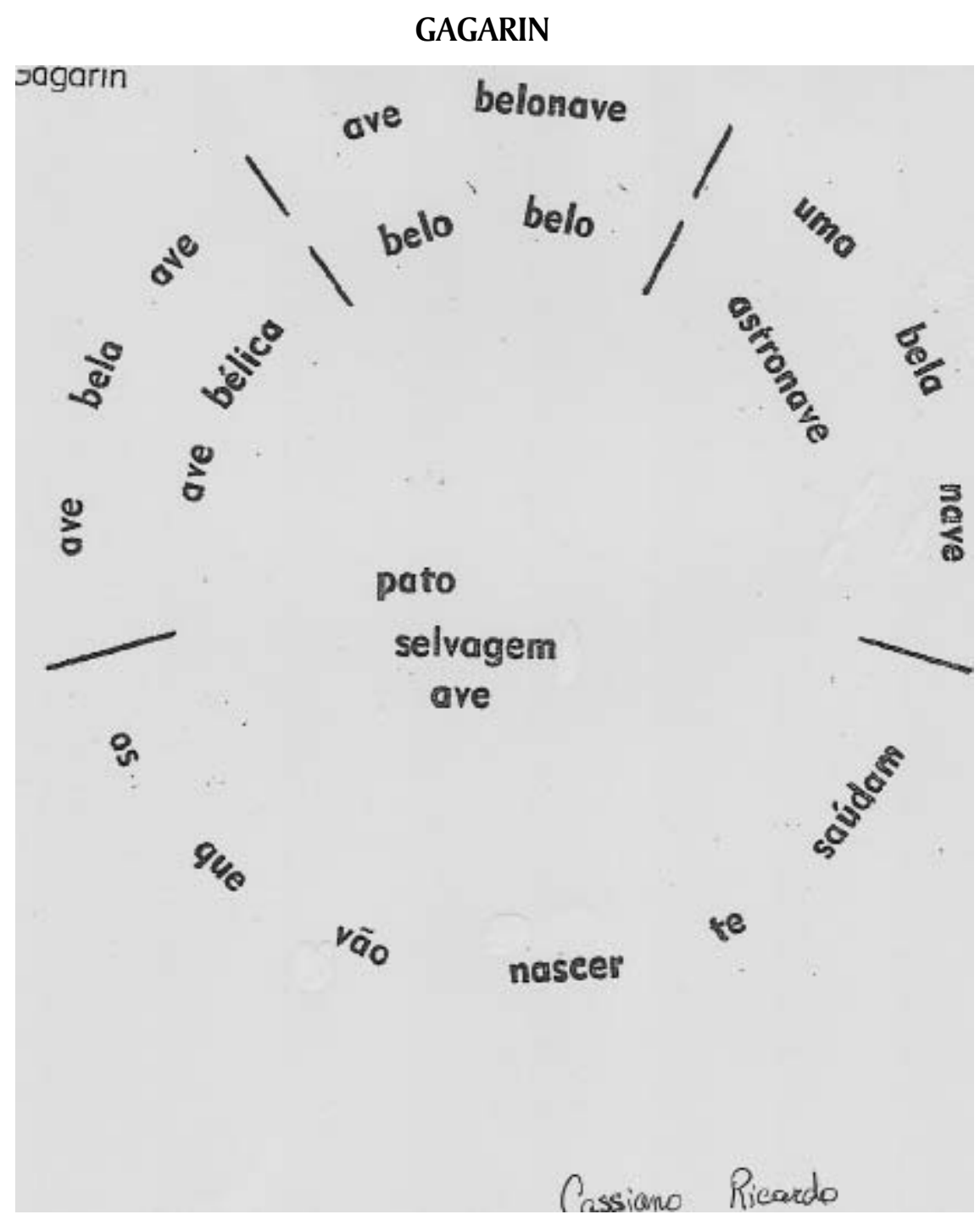

In: Invenção no 1. São Paulo: Massao Ohno Editor, 1962. 
GOLDSTEIN, Norma Seltzer. Gênero poético: uma proposta em espiral para o ensino...

Nos anos 70 do século XX, um grupo de jovens criava poemas distribuídos em folhas mimeografadas, de modo criativo, crítico e irônico. É a chamada geração dos anos 70. Vale observar como o aspecto visual complementa o verbal no poema que se segue:

\begin{tabular}{|l|}
\hline PEGA LADRÃO! \\
\hline Alguém tirou \\
um pedaço \\
do meu \\
$\mathrm{P} \sim \mathrm{O}$ \\
\hline
\end{tabular}

Katia Bento. Poesia Jovem-Anos 70. Seleção de textos, notas, estudo crítico e histórico de Heloísa Buarque de Hollanda et al., São Paulo: Abril Cultural, 1982, p. 91.

O bom humor da composição decorre do formato do poema: a visualização do "furto" pela elipse da vogal "a" da última palavra, compondo em destaque o verso final.

\section{0}

Os exemplos comentados são apenas sugestões de como se pode trabalhar o poema nas aulas de Língua Portuguesa, desde que, na escola, essa atividade ocorra sempre de forma contextualizada. Sugerimos desenvolver o trabalho de modo a retomar os tipos de poemas já lidos antes pela classe, a fim de compará-los com os novos modos de compor a serem introduzidos a cada etapa. Acreditamos que esse processo "em espiral" solidifica a experiência dos leitores - e produtores - de poesia, complementando pouco a pouco o elenco de recursos expressivos presentes no texto poético, de modo a levar os alunos a reconhecê-los e empregá-los cada vez mais e melhor. Como resultado paralelo, mas nada desprezível, são apresentadas várias noções acerca de como se constroem os efei- 
Filol. lingüíst. port., n. 8, p. 361-377, 2006.

tos de sentido, incluindo tanto aspectos que funcionam na linguagem em geral, poética ou não (como os morfossintáticos, os semânticos e os de construção de figuras de linguagem) quanto aqueles mais específicos do poema (como a métrica, o ritmo, a organização particular), sem perder de vista a conjunção entre a linguagem verbal e o não verbal.

\section{BIBLIOGRAFIA}

DOLZ, J. e PASQUIER, A. (1996). "Un decálogo para enseñar a escribir". In: Cultura y educación, 2. Madrid, Infancia Y Aprendizage, p. 31-42.

JAKOBSON, R. (1969). “Lingüística e Poética. In: Lingüística e comunicação. São Paulo: Cultrix. LOLIBERT, J. (1994). Formando crianças produtoras de texto. Porto Alegre: Artmed.

LEVIN, S. (1975). Estruturas lingüísticas em poesia. São Paulo: Cultrix/ Edusp.

MAINGUENEAU, D. (1990). Elements de linguistique pour le texte littéraire. Paris: Bordas.

PROENÇA, M. C. (1955). Ritmo e poesia. Rio de Janeiro: Simões.

TODOROV et al. (1982). 0 discurso da poesia. Coimbra: Almedina.

RÉSUMÉ: Travailler la poesia a l'ecole devient particulierement interessant si l'on choisit un procede "en spirale". Dans ce sens, voila comment ce texte propose de travailler le poème dans le "ensino fudamental ii bresilien" (eleves de 11 a 14 ans): I) lecture et reconnaissance des caracteristiques des poèmes reguliers et irreguliers, a 11 et 12 ans; II) prose poetique et poème en prose, a 13 ans; iii) poèmes visuels, a 14 ans. Ce travail doit considerer qu' en situation scolaire l'enseignement doit toujours se faire en contexte.

MOTS-CLÉS: Le texte poétique à l'école; Lecture de poésie; Le poème et l'étude de la langue. 